Marquette University

e-Publications@Marquette

$7-2007$

\title{
Temporally Graded Activation of Neocortical Regions in Response to Memories of Different Ages
}

\author{
John L. Woodard \\ Wayne State University \\ Michael Seidenberg \\ Rosalind Franklin University of Medicine and Science \\ Kristy A. Nielson \\ Marquette University, kristy.nielson@marquette.edu \\ Sarah K. Miller \\ Rosalind Franklin University of Medicine and Science \\ Malgorzata Franczak \\ Medical College of Wisconsin
}

See next page for additional authors

Follow this and additional works at: https://epublications.marquette.edu/psych_fac

Part of the Psychology Commons

\section{Recommended Citation}

Woodard, John L.; Seidenberg, Michael; Nielson, Kristy A.; Miller, Sarah K.; Franczak, Malgorzata; Antuono, Piero; Douville, Kelli; and Rao, Stephen M., "Temporally Graded Activation of Neocortical Regions in Response to Memories of Different Ages" (2007). Psychology Faculty Research and Publications. 114.

https://epublications.marquette.edu/psych_fac/114 


\section{Authors}

John L. Woodard, Michael Seidenberg, Kristy A. Nielson, Sarah K. Miller, Malgorzata Franczak, Piero Antuono, Kelli Douville, and Stephen M. Rao 


\title{
Temporally Graded Activation of Neocortical Regions in Response to Memories of Different Ages
}

\author{
John L. Woodard ${ }^{1,2}$, Michael Seidenberg ${ }^{1,2}$, Kristy A. Nielson ${ }^{2,3}$, \\ Sarah K. Miller ${ }^{1,2}$, Malgorzata Franczak ${ }^{2}$, Piero Antuono ${ }^{2}$, \\ Kelli L. Douville ${ }^{1,2}$, and Stephen M. Rao ${ }^{2}$
}

\begin{abstract}
The temporally graded memory impairment seen in many neurobehavioral disorders implies different neuroanatomical pathways and/or cognitive mechanisms involved in storage and retrieval of memories of different ages. A dynamic interaction between medial-temporal and neocortical brain regions has been proposed to account for memory's greater permanence with time. Despite considerable debate concerning its time-dependent role in memory retrieval, medialtemporal lobe activity has been well studied. However, the relative participation of neocortical regions in recent and remote memory retrieval has received much less attention. Using functional magnetic resonance imaging, we demonstrate
\end{abstract}

\section{INTRODUCTION}

A number of neurobehavioral disorders exhibit retrograde memory impairment characterized by a "temporal gradient," in which remote memories are better preserved than more recently learned information. The notion of temporally graded memory impairment dates to Ribot (1881), who suggested that brain injury disrupts premorbid memories in the inverse order of their development. The temporal gradient is of considerable theoretical importance to neuroscientists for several reasons. First, temporally graded memory impairment implies a different cognitive mechanism for the storage and retrieval of memories of differènt ages (e.g., Conway \& Haque, 1999; Fitzgerald, 1996). Older memories appear to have established a greater permanence than more recent memories in this "first-in, last-out" organization. Second, the varieties of neuropathological lesions that produce temporally graded memory impairment suggest differences in the neuroanatomical substrates that support recent and remote memory retrieval (e.g., Moscovitch, Nadel, Winocur, Gilboa, \& Rosenbaum,

\footnotetext{
${ }^{1}$ Rosalind Franklin School of Medicine and Science, North Chicago, IL, ${ }^{2}$ Medical College of Wisconsin, ${ }^{3}$ Marquette University, Milwaukee, WI
}

robust, temporally graded signal differences in posterior cingulate, right middle frontal, right fusiform, and left middle temporal regions in healthy older adults during famous name identification from two disparate time epochs. Importantly, no neocortical regions demonstrated greater response to older than to recent stimuli. Our results suggest a possible role of these neocortical regions in temporally dating items in memory and in establishing and maintaining memory traces throughout the lifespan. Theoretical implications of these findings for the two dominant models of remote memory functioning (Consolidation Theory and Multiple Trace Theory) are discussed.
2006; McClelland, McNaughton, \& O'Reilly, 1995; Butters \& Cermak, 1986). Finally, the temporal gradient has traditionally been thought to reflect a dynamic interaction between medial-temporal and neocortical brain regions, whereby memories achieve permanence with time (Moscovitch \& Nadel, 1998; Nadel \& Moscovitch, 1997; Squire \& Alvarez, 1995). However, the nature of this interaction and the relative roles of the medialtemporal lobe and the neocortex during retrieval of memories of different ages remain to be established.

Functional neuroimaging has only recently been used to study these aspects of remote memory retrieval. Although the role of the medial-temporal lobe in recent and remote memory functioning has been well studied, there is still considerable debate regarding the necessary involvement of this region in retrieval of older memories (Moscovitch \& Nadel, 1998; Nadel \& Moscovitch, 1997; Squire \& Alvarez, 1995). Furthermore, because the principal focus of most previous investigations has been on the medial-temporal lobe, the relative involvement of neocortical regions in recent and remote memory retrieval has received much less attention. Retrieval of autobiographical material (Maguire \& Frith, 2003; Ryan et al., 2001) or recognition of famous faces (Bernard et al., 2004; Haist, Bowden Gore, \& Mao, 2001) and names (Douville et al., 2005) is consistently associated with 
medial-temporal lobe activation, regardless of whether the memoranda are of recent or remote origin, with one exception (Haist et al., 2001). Temporally graded hippocampal activation, with recent stimuli evoking greater activation than remote material, has been reported in right-hemisphere medial-temporal lobe structures (Douville et al., 2005; Maguire \& Frith, 2003; Haist et al., 2001), with exceptions noted in studies using recognition of recent and remote famous faces (Bernard et al., 2004) and recognition of recent and remote family photographs (Gilboa, Winocur, Grady, Hevenor, \& Moscovitch, 2004).

With respect to temporally graded neocortical activity, parametric decreases have been observed in right ventrolateral prefrontal cortex activity with increasing remoteness for autobiographical (but not public) events (Maguire, Henson, Mummery, \& Frith, 2001). They proposed that the degree of activation in this region may correspond to the degree of integration of the memory trace with contextual information (which may serve as a cue for a memory trace), tending to decline with increasing memory age. Gilboa et al. (2004) reported increased activation in the retrosplenial cortex for recent memories regardless of their vividness, in addition to increased activity in the inferolateral temporo-occipital cortex in response to remote memories. In contrast, Bernard et al. (2004) compared recognition of famous faces from the 1960 s to the 1970 s with famous faces from the 1990 s, but no evidence of temporally graded activity was noted in medial-temporal or neocortical brain regions. However, the remote stimuli used in this study were persons with relatively enduring fame (e.g., John F. Kennedy). Therefore, memory traces associated with these remote stimuli may have been updated regularly, perhaps with a frequency that was similar to that of the recent stimuli.

A better understanding of the neocortical response to memories of different ages would address a number of yet unanswered questions regarding aspects of remote memory. For example, it would help determine the degree to which the neocortex participates early in the formation of a memory and whether this activity is maintained throughout the life of the memory. Also, initial theoretical accounts of the neocortical-hippocampal interaction during recent and remote memory retrieval have not been very specific regarding the location and expected time course of activity in the neocortex (cf. Moscovitch \& Nadel, 1998; Nadel \& Moscovitch, 1997; Squire \& Alvarez, 1995). However, recent studies have suggested that the prefrontal cortex may play a significant role in remote spatial memory retrieval and contextual fear conditioning (Frankland \& Bontempi, 2005; Bontempi, Laurent-Demir, Destrade, \& Jaffard, 1999; but scc Rudy, Bicdenkapp, \& O'Reilly, 2005 for an alternative account of the role of the prefrontal cortex in remote memory retrieval). The prefrontal cortex may also potentially play a role in human remote memory retrieval by virtue of its involvement in performance monitoring and strategic search and retrieval of previously learned information (Ridderinkhof, Ullsperger, Crone, \& Nieuwenhuis, 2004; Fletcher \& Henson, 2001). Indeed, Takashima et al. (2006) have reported an increase in neural activity in the medial prefrontal cortex (as well as a corresponding decrease in hippocampal activity) during retrieval of declarative memories after only 1 month.

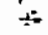

In a previous functional magnetic resonance imaging (fMRI) study conducted on healthy older adults (Douville et al., 2005), we compared activation patterns emanating from the medial-temporal lobe (bilateral hippocampal complex and parahippocampal gyrus) in response to a carefully standardized set of famous names from the 1950 s (remote) and the 1990 s (recent) relative to unfamiliar names. Our remote names were famous persons who were out of the public eye for many years, making their memory traces less likely to have been updated recently. The right hippocampal complex and the parahippocampal gyrus showed a temporally graded response (Recent > Remote > Unfamiliar), whereas the left hippocampal complex and the parahippocampal gyrus demonstrated significantly greater activation in response to the famous names, regardless of time epoch, relative to unfamiliar names (Recent $=$ Remote $>$ Unfamiliar). Importantly, all medial-temporal lobe structures showed increased activity in response to botb recently acquired (within 5-10 years) and remotely acquired (within 4050 years) famous names, relative to unfamiliar names. In the current study, which is based on the same imaging dataset, we now focus our attention on changes in neocortical activation during recognition of recent and remote famous names in the same group of healthy older adults.

\section{METHODS}

\section{Participants}

Participants were 15 healthy older adults (10 women and 5 men) with a mean age of 70.4 years $(S D=6.4$ years, range $=60-79$ years) and a mean education of 15.4 years $(S D=2.5$ years, range $=12-20$ years $)$. Participants were strongly right-handed (mean laterality quotient $=92.7$, range $=84-100)$ on the Edinburgh Handedness Inventory (Oldfield, 1971). None of the participants reported a history of neurological disease, major psychiatric disturbance, substance abuse, or were taking psychoactive prescriptive medications. Prior to the scanning session, participants underwent cognitive screening. All participants performed within normal limits on the Mini-Mental State Examination (Folstein, Folstein, \& McHugh, 1975) $[$ mean $=29.2, S D=0.97$, range $=27-30]$ and on the Repeatable Battery for Assessment of Neuropsychological Status (Randolph, 1998; Randolph, Tierney, Mohr, \& Chase, 1998) $[$ mean $=105.1, S D=12.1$, range $=95$ 129]. Informed consent was obtained from participants according to the institutional guidelines established by 
the Medical College of Wisconsin Human Subjects Review Committee. Participants were compensated for their time.

\section{Stimuli}

Name stimuli were selected through a carefully standardized pilot study conducted on 24 young and 24 older individuals (Douville et al., 2005). From an initial corpus of 784 famous names selected from the Internet, trivia books, and magazines and newspapers, along with unfamiliar names selected from a metropolitan telephone directory, a pool of 30 names from each of four categories were obtained. Stimuli consisted of persons who achieved public prominence between 1990 and 2000 (Recent stimuli: correctly identified by $90 \%$ of older and younger participants), persons who achieved prominence between 1950 and 1965 but who have been out of the public eye for some time and are not as likely to appear frequently in the news or entertainment media (Remote stimuli: correctly identified by $90 \%$ of older and only $10 \%$ of younger participants), and unfamiliar names (Unfamiliar stimuli: correctly identified as unfamiliar by $90 \%$ of older and younger participants). A fourth stimulus category that was included, bur was not directly examined, in this study represented persons who achieved fame between 1950 and 1965 and are still well-known (correctly identified by $90 \%$ of older and younger participants).

\section{Procedure}

\section{Imaging Task}

Participants viewed a series of individually presented names and were asked to indicate using a button press whether the presented name was that of a famous individual. Name stimuli were presented visually in a random order at the rate of $4 \mathrm{sec}$ per stimulus. Inactive periods (4 sec), consisting of a single centrally placed fixation crosshair, were randomly interspersed in a 2:1 ratio (name/fixation trials). Participants were requested to respond to names judged to be famous by making a right index finger keypress, while they were asked to make a right middle finger keypress in response to names judged to be unfamiliar. Stimuli were presented in three imaging runs of 30 trials each (10 stimuli from each of the three name conditions, 15 fixation trials). Twelve seconds of fixation were added to both the beginning and the end of each run. Run order was counterbalanced across subjects.

\section{Functional Magnetic Resonance Imaging}

Whole-brain, event-related AMRI was conducted on a commercial 1.5-Tesla scanner (Signa; General Electric Medical Systems, Milwaukee, WI) equipped with a threeaxis local gradient head coil and an elliptical end-capped quadrature radio-frequency coil (Medical Advances, Milwaukee, WT). Echo-planar images were collected using a single-shot, blipped, gradient-echo echo-planar pulse sequence [echo time (TE), $40 \mathrm{msec}$; field of view (FOV), $24 \mathrm{~cm}$; matrix size, $64 \times 64$ ]. For the three imaging runs, 22 contiguous sagittal 6 -mm-thick slices were selected to provide coverage of the entire brain (voxel size $=3.75 \times 3.75 \times 6 \mathrm{~mm}$ ). The interscan interval [repetition time (TR)] was $2 \mathrm{sec}$. During each imaging series, 132 sequential echo-planar images were collected. At the beginning of the scan session, high-resolution, three-dimensional spoiled gradient-recalled at steadystate (SPGR) anatomic images were acquired [TE = $5 \mathrm{msec} ; \mathrm{TR}=24 \mathrm{msec}$; flip angle $=40^{\circ}$; number of excitations $($ NEX) $=1$; slice thickness $=1.2 \mathrm{~mm}$; FOV $=$ $24 \mathrm{~cm}$; resolution $=256 \times 192]$. Foam padding was used to reduce head movement within the coil.

Functional images were generated using the Analysis of Functional NeuroImages (AFNI) software package (Cox, 1996). Each image time series was spatially registered in-plane to reduce the effects of head motion using an iterative linear least squares method. A deconvolution analysis was used to extract separate hemodynamic response functions (HRFs) for each of the three types of name stimuli used in this study. In addition, only correct responses (true positives for famous names and true rejections for unfamiliar names) were incorporated into the estimate of the HRF for each stimulus type. HRFs were modeled for the $2-14 \mathrm{sec}$ period poststimulus onset. Individual anatomical and functional scans were linearly interpolated to $1 \mathrm{~mm}^{3}$ voxels, coregistered, and transformed into standard stereotaxic space (Talairach \& Tournoux, 1988). To compensate for normal variation in anatomy across subjects, functional images were blurred using a 4-mm Gaussian fullwidth half-maximum filter.

\section{Voxelwise Analysis}

Three voxelwise t-test subtractions were conducted on the area under the curve (AUC) of the HRF at 4,6, and 8 sec poststimulus onset: Recent - Unfamiliar, Remote Unfamiliar, Recent - Remote). A voxelwise statistical threshold was applied $[t(14)=3.787, p<.001]$, along with a minimum cluster size threshold (Forman et al., 1995) of $0.250 \mu \mathrm{l}$, in order to minimize false-positive activation foci from the brain maps.

\section{Functional Region-of-Interest Analysis}

Thirteen functional regions of interest (ROIs) were defined by conjoining the results of the three voxelwise comparisons. Any voxel deemed "activated" by the Recent - Unfamiliar, Remote - Unfamiliar, or Recent Remote voxelwise subtractions contributed to the final functional ROI map (see Table 2). Averaged HRFs were then calculated for each of the 13 functional ROIs for 
each subject as a function of stimulus type. For each region, one-way repeated-measures analyses of variance (ANOVAS) were conducted on the AUC estimates for each name condition. These analyses were followed by pooled variance $t$ tests with Bonferroni-corrected significance levels to compare each of the conditions in a pairwise manner (Recent vs. Unfamiliar, Remote vs. Unfamiliar, Recent vs. Remote).

\section{RESULTS}

Accuracy (correct recognition of famous names, correct rejection of unfamiliar names) exceeded $90 \%$ correct and did not differ across stimulus categories $\left[M_{\text {kecent }}=\right.$ $92.8 \%, S D=8.6,95 \%$ Confidence interval $(C I)=88.0 \%$ to $97.6 \% ; M_{\text {Remote }}=90.3 \%, S D=7.9,95 \% \mathrm{CI}=85.9 \%$ to $94.7 \% ; M_{\text {Unfamiliar }}=94.6 \%, S D=6.4,95 \% \mathrm{CI}=91.1 \%$ to $98.1 \% ; F(2,28)=1.30, p=.288 \mid$. Reaction times (R'Ts) differed across the three categories $[F(2,28)=12.90$, $p<.001$ ], with RTs for rejection of unfamiliar stimuli $(M=1540 \mathrm{msec}, S D=388)$ being slower than for recognition of recent $(M=1317 \mathrm{msec}, S D=287)$ and remote $(M=1242 \mathrm{msec}, S D=248)$ famous names; importantly, RTs for the remote and recent famous names were not significantly different $(p=.20)$.

Three voxelwise comparisons were performed across the three name conditions: Remote versus Unfamiliar, Recent versus Unfamiliar, Recent versus Remote. Significant clusters of activation for each comparison are presented in Table 1 and Figure 1. Relative to unfamiliar names, remote lamous names showed significant activations in the posterior cingulate, left superior frontal gyrus, bilateral middle temporal gyrus, anterior cingulate, right caudate, left precuneus, right fusiform gyrus, and left middle and medial frontal gyrus. The RecentUnfamiliar comparison resulted in a generally larger spatial extent of activation than the Remote-Unfamiliar comparison in most of the same brain regions. Additional areas showing significant activations in the RecentUnfamiliar contrast included the left anterior middle temporal gyrus, the right parahippocampal gyrus, the left precuneus, the left inferior frontal gyrus, and the right middle frontal gyrus. However, the significant clusters seen in the left middle and medial frontal gyri and

Table 1. Locations of Active Clusters by Comparison

\begin{tabular}{|c|c|c|c|c|c|c|c|c|c|c|c|c|}
\hline \multirow[b]{3}{*}{ Region } & \multicolumn{12}{|c|}{ Comparison } \\
\hline & \multicolumn{4}{|c|}{ Recent $>$ Unfamiliar } & \multicolumn{4}{|c|}{ Remote $>$ Unfamiliar } & \multicolumn{4}{|c|}{ Recen $>$ Remote } \\
\hline & Volume (jil) & $x$ & $y$ & $z$ & Volume $(\mu l)$ & $x$ & $y$ & $z$ & Volume $(\mu l)$ & $x$ & $y$ & $z$ \\
\hline Posterior cingulate & 17,111 & -2 & -50.9 & 19.6 & 5653 & 0.1 & -49.9 & 18.3 & 296 & -4.6 & -55.2 & 28 \\
\hline Anterior cingulate & 885 & 0.4 & 44.8 & 1.8 & 1175 & 1.2 & 44 & 0.4 & & & & \\
\hline Left inferior frontal gyrus & 357 & -45.9 & 21.7 & 1 & & & & & & & & \\
\hline Left superior frontal gyrus & 7844 & -17.5 & 28.9 & 41.3 & 2263 & -18.8 & 24.9 & 46.2 & & & & \\
\hline Left middle frontal gyrus & & & & & 672 & -28.9 & 10.2 & 55 & & & & \\
\hline Left medial frontal gyrus & & & & & 441 & -6.6 & 49.1 & 20 & & & & \\
\hline Left medial frontal gyrus & & & & & 417 & -9.2 & 41.1 & 34.3 & & & & \\
\hline Right middle frontal gyrus & 272 & 23.7 & 19.4 & 40.9 & & & & & & & & \\
\hline $\begin{array}{l}\text { Left middle temporal } \\
\text { gyrus }\end{array}$ & 1700 & -56.6 & -39.6 & -6.5 & 263 & -60.3 & -39.4 & -6.8 & & & & \\
\hline $\begin{array}{l}\text { Left anterior middle } \\
\text { temporal gyrus }\end{array}$ & 526 & -53.8 & -12.3 & -13.5 & & & & & & & & \\
\hline $\begin{array}{l}\text { Left posterior middle } \\
\text { temporal gyrus }\end{array}$ & 4453 & -44 & -68.6 & 23 & 1698 & -45.4 & -67.9 & 21.8 & & & & \\
\hline $\begin{array}{l}\text { Right middle temporal } \\
\text { gyrus }\end{array}$ & 1275 & 48 & -60.8 & 12.4 & 252 & 51.3 & -61.1 & 13.2 & & & & \\
\hline Right fusiform gyrus & & & & & 255 & 26.3 & -40.2 & -18 & & & & \\
\hline $\begin{array}{l}\text { Right parahippocampal } \\
\text { gyrus }\end{array}$ & 486 & 23.8 & -19.6 & -11.9 & & & & & & & & \\
\hline Right caudate & 468 & 15.6 & 5.2 & 18.6 & 348 & 12.9 & 3.2 & 19.6 & & & & \\
\hline Left precuneus & 365 & -11.2 & -51.3 & 45.8 & & & & & & & & \\
\hline
\end{tabular}


Figure 1. Regions of significant activation for the three principal time epoch contrasts: Recent $>$ Unfamiliar, Remote $>$ Unfamiliar, Recent $>$ Remote. Table 1 provides region locations and coordinates for local maxima.

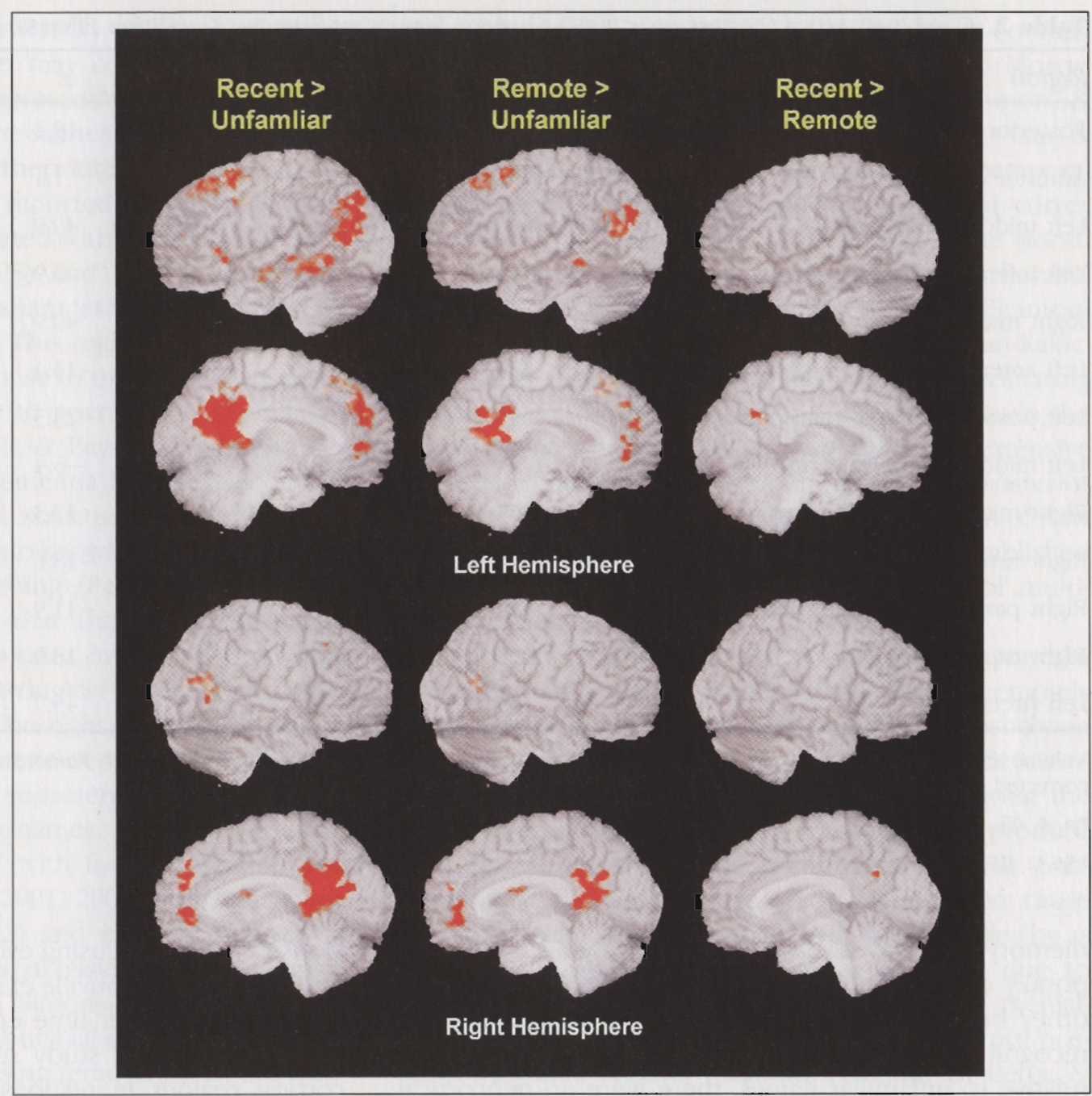

the right fusiform gyrus in the Remote-Unfamiliar contrast were not observed in the Recent-Unfamiliar contrast. No areas demonstrated greater activation for the unfamiliar relative to familiar names. The comparison of remote and recent famous name conditions revealed a significant cluster of activation exclusively in the posterior cingulate cortex, suggesting evidence of a temporally graded response with stimulus age (Recent $>$ Remote). There were no areas that demonstrated greater activation in the remote relative to recent conditions.

A functional ROI analysis (see Methods) was performed as a follow-up to the voxelwise analysis to evaluate possible differences across conditions in MR signal intensity, as reflected by the AUC of the HRF. Averaged HRFs were computed from a conjunction map consisting of 13 regions derived from the voxelwise analysis (Table 2). Repeated-measures ANOVAs revealed significant omnibus differences $(p<.001)$ across the three name conditions (Table 2). Bonferroni-corrected pairwise comparisons $(p<.05)$ demonstrated significantly greater MR signal intensity change in the HRF for the recent famous names relative to the unfamiliar names for all 13 regions, and significantly greater MR signal intensity change for the remote famous names relative to the unfamiliar names for all regions except the left precuneus. Significantly greater MR signal intensity change, indicating a temporal gradient effect, was seen for the recent famous names relative to the remote famous names in the posterior cingulate, left middle temporal gyrus, right middile frontal gyrus, and right fusiform gyrus (Figure 2).

\section{DISCUSSION}

In this event-related fMRI study, we demonstrate that retrieval of recent and remote memories differentially activates several neocortical regions, including the posterior cingulate, right middle frontal and fusiform, and left middle temporal areas, with decreasing activation seen in response to older stimuli. All neocortical regions showed either no difference or a temporally graded decline in activity in response to older stimuli. Given the differential response of these brain regions to memories of different ages, these areas may act in concert with the hippocampal complex and the diencephalon to establish new memory traces as well as to reactivate established memory traces associated with older memories. The differential response of these regions to 
Table 2. Combined Active Clusters $(p<.001)$ Showing Significant Stimulus Condition Effects

\begin{tabular}{|c|c|c|c|c|c|c|}
\hline Region & Volume (ul) & $x$ & $y$ & $z$ & $F(2,28)$ & Significance \\
\hline Posterior cingulate & 17,438 & -1.6 & -50.5 & 19.2 & 45.6 & $\mathrm{a}, \mathrm{b}, \mathrm{c}^{* *}$ \\
\hline Anterior cingulate & 1592 & 0.7 & 44.5 & 1.1 & 22.2 & $a, b$ \\
\hline Left middle frontal gyrus & 8688 & -17.6 & 28.6 & 40.9 & 48.51 & $\mathrm{a}, \mathrm{b}$ \\
\hline Left inferior frontal gyrus & 357 & -46 & 21.6 & 0.9 & 26.89 & $a, b$ \\
\hline Right middle frontal gyrus & 272 & 23.7 & 19.4 & 40.9 & 16.48 & $a, b^{*}, c^{*}$ \\
\hline Left anterior middle temporal gyrus & 526 & -54 & -12.6 & -13.4 & 46.57 & $a, b$ \\
\hline Left posterior middle temporal gyrus & 4695 & -44.1 & -68.1 & 23.3 & 39.82 & $a, b$ \\
\hline Left middle temporal gyrus & 1774 & -56.8 & -39.4 & -6.4 & 38.33 & $a, b, c^{*}$ \\
\hline Right middle temporal gyrus & 1377 & 48.4 & -60.6 & 12.3 & 34.15 & $a, b$ \\
\hline Right fusiform gyrus & 255 & 26.1 & -40.2 & -18.6 & 25.8 & $a, b, c^{* *}$ \\
\hline Right parahippocampal gyrus & 486 & 23.7 & -19.6 & -11.9 & 22.12 & $\mathrm{a}, \mathrm{b}$ \\
\hline Right caudate & 698 & 14.4 & 4.1 & 18.9 & 37.55 & $a, b$ \\
\hline Left precuneus & 365 & -11 & -51.1 & 45.7 & 31.08 & $a, c$ \\
\hline
\end{tabular}

Volume represents microliters $(\mu \mathrm{l}) ; \mathrm{a}=$ Recent $>$ Unfamiliar; $\mathrm{b}=$ Remote $>$ Unfamiliar; $\mathrm{c}=$ Recent $>$ Remore; all $p$ values for $F$ and for Bonferronicorrected post hoc comparisons across conditions are significant at $p<.001$ except where noted.

$* p<.05$.

$* p<.01$.

memory age may also serve as a mechanism for temporally dating items in memory. Although a number of other brain regions showed activation in response to recognition of both recent and remote famous names relative to unfamiliar names, there were no neocortical regions that demonstrated greater activation in response to older stimuli. Combined with the results of our pre- vious ROI study focusing exclusively on medial-temporal lobe structures (Douville et al., 2005), as well as research investigating briefer time epochs (Rekkas \& Constable, 2005), the current study suggests that activity of neocortical regions in response to retrieval of memories of different ages largely parallels that of the medialtemporal lobe.

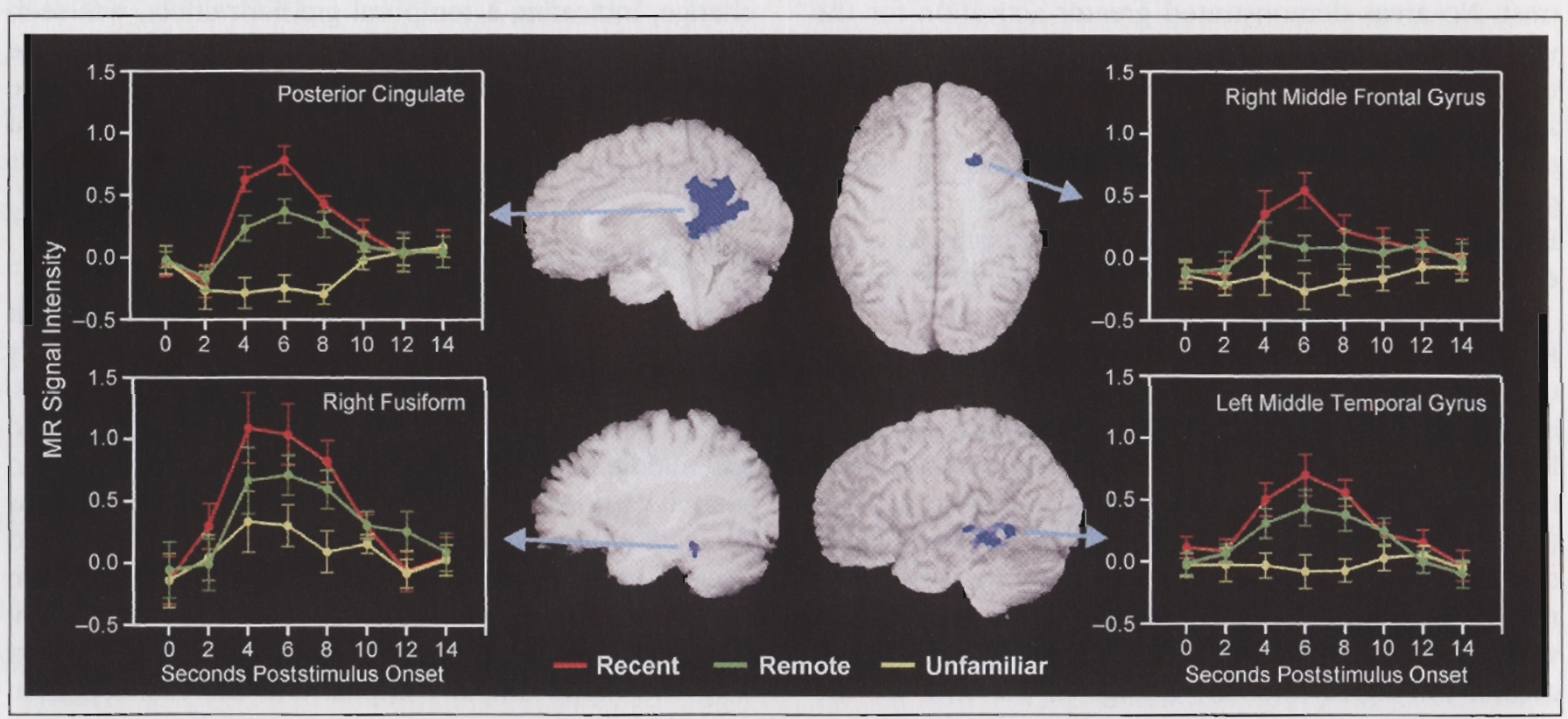

Figure 2. The four regions that demonstrated evidence of at temporally graded response to names from different time epochs are depicted with anatomical localization and full time-course, group-averaged HRFs. Significant time epoch differences were identified using cstimates of the hemodynamic response (AUC for $4-8 \mathrm{sec}$ poststimulus). Error bars reflect the standard error of measurement at each time point. 
The temporally graded activation we observed in the left middle temporal region may correspond to timedependent changes in the representation of verbal memory traces associated with the names of familiar persons (Leveroni et al., 2000). Furthermore, activation in this region has previously been reported during retrieval of semantic information associated with famous individuals (Gorno-Tempini et al., 1998) and during a semantic memory retrieval task (Graham et al., 2000, cited in Patterson \& Hodges, 2000). This region has also shown increased activation in response to previously presented (i.e., familiar) items relative to novel items (Yonelinas, Hopfinger, Buonocore, Kroll, \& Baynes, 2001). Studies of patients with semantic dementia have revealed focal atrophy in lateral temporal structures, and these patients show impaired semantic knowledge that contrasts with intact anterograde leaning (Patterson \& Hodges, 2000). Thus, it is possible that this region may support semanticization of memories over time (Snowden, Griffiths, \& Neary, 1996; Warrington \& McCarthy, 1988; Butters \& Cermak, 1986). The right fusiform activation may correspond to similar time-dependent changes in visuospatial person-identity representations (e.g., faces) associated with the famous names. The right fusiform region has been associated with face recognition and processing (Sperling et al., 2001, 2003; Bernstein, Beig, Siegenthaler, \& Grady, 2002) and may be involved in processing specific features of visual objects (Garoff, Slotnick, \& Schacter, 2005; Simons, Koutstaal, Prince, Wagner, \& Schacter, 2003; Koutstaal et al., 2001). For example, a decline with increasing remoteness in the association between a person's name and the mental image associated with the name may occur (Pigott \& Milner, 1993). Temporally graded activity in the right middle frontal regions might be associated with strategic memory search (Ridderinkhof et al., 2004; Fletcher \& Henson, 2001). Although the region of activation in this study was more lateral and dorsal compared to the ventromedial area reported by Takashima et al. (2006), it may, nevertheless, reflect a neocortical memory storage site. Interestingly, increases in cortical thickness in this region have been associated with recall of verbal material after months, but not after minutes (Walhovd et al., 2006). Given the substantial temporally graded activation associated with the posterior cingulate region, we consider the role of this region in memory functioning in greater detail below.

\section{Posterior Cingulate Cortex and Memory Functioning}

The finding of greater activation of the posterior cingulate to recent relative to remote memories may provide some clues as to its role in establishing and maintaining memory traces. Given the extensive reciprocal connections between the posterior cingulate and cells that give rise to the perforant pathway into the hippocam- pus (Kobayashi \& Amaral, 2003), as well as its connections with the mid-dorsolateral prefrontal cortex (Morris, Pandya, \& Petrides, 1999; Goldman-Rakic, Selemon, \& Schwartz, 1984), anterior thalamic nuclei (Shibata \& Yukie, 2003; Amaral \& Cowan, 1980), superior temporal sulcus (Morris et al., 1999), posterior parietal cortex (Morris et al., 1999; Kolb \& Walkey, 1987), the dorsal visual system dedicated to spatial processing (Kobayashi \& Amaral, 2003), and the frontal eye fields (Stanton, Bruce, \& Goldberg, 1995; Selemon \& Goldman-Rakic, 1988), this region may play a key role in coordinating multimodal input from a variety of brain regions in the formation of a memory trace. By virtue of its extensive interconnections with other brain regions, the posterior cingulate region may participate in the formation of new memory traces and in the reactivation of established memory traces by providing varying degrees of multimodal input.

Our finding that the posterior cingulate region played a pivotal role in retrieving names of recently and remotely famous individuals is consistent with findings showing that lesions in this region can produce retrograde memory impairment. As early as 1929 , tumors involving the retrosplenial/posterior cingulate were noted to produce memory disorders (Ironside \& Guttmacher, 1929). Subsequent studies indicated that such lesions can cause visual perceptual impairment, as well as retrograde (by as much as 10 years) and anterograde amnesia, due to disruption of the thalamocortical input to the medialtemporal lobe that traverses through retrosplenial/posterior cingulate regions (Gainotti, Almonti, Di Betta, \& Silveri, 1998; Rudge \& Warrington, 1991; Valenstein et al., 1987). Furthermore, a number of neuroimaging studies have extended the findings of human lesion reports, suggesting that metabolic activity and perfusion in the posterior cingulate region may be impaired in patients with disorders associated with temporally graded preservation of earlier memories, such as mild cognitive impairment, Alzheimer's disease, and Wernicke--Korsakoff syndrome (Eustache er al., 2004; Ivanoiu, Cooper, Shanks, \& Venneri, 2004; Huang, Wahlund, Svensson, Winblad, \& Julin, 2002; Tanaka et al., 2002; Kazui et al., 2000; Greene, Hodges, \& Baddeley, 1995; Hodges, Salmon, \& Butters, 1993; Kopelman, 1989) and even in persons with genetic susceptibility to develop Alzheimer's disease (Reiman et al., 1996, 2001; Small et al., 2000).

Functional activation studies of healthy individuals have demonstrated a prominent role of the retrosplenial/ posterior cingulate region not only in episodic memory retrieval and familiarity (Henson, Rugg, Shallice, Josephs, \& Dolan, 1999; Rugg, Fletcher, Frith, Frackowiak, \& Dolan, 1997; Fletcher, Shallice, Frith, Frackowiak, \& Dolan, 1996; Fletcher et al., 1995; Nyberg et al., 1995; Grasby et al., 1993) but also during the acquisition and retrieval of public and autobiographical person familiarity (Gilboa et al., 2004; Maddock, Garrett, \& Buonocore, 2001; Shah et al., 2001; Leveroni et al., 2000). Affective 
associations with famous names may also change with time and might underlie the temporally graded response seen in this region (Maddock, 1999; Fink et al., 1996). Wagner, Shannon, Kahn, and Buckner (2005) provide an excellent review of additional roles of the retrosplenialy posterior cingulate region and the surrounding parietal cortex in a variety of aspects of memory functioning. Thus, the posterior cingulate region appears to play a substantial role in the general acquisition and retrieval of episodic memories, familiaricy, and person identity information in particular. Our study extends these findings by demonstrating that the posterior cingulate region shows evidence of temporally graded activity in response to recognition of person-idencity information for publicly famous individuals learned as long as 50 ycars earlier.

\section{Theoretical Implications}

Consolidation Theory (Squire \& Alvarez, 1995) attributes a critical role to the hippocampal complex for retrieving recently learned (but not remotely learned) information and acknowledges a dynamic interaction between medial-temporal structures and neocortical regions early in the formation of a memory. Consolidation Theory does not explicitly specify whether or how neocortical activity might be expected to differ between recent and remote memory retrieval, although decreasing medial-temporal lobe involvement in response to older memories was clearly proposed. However, other investigators have suggested that Consolidation Theory would predict that retrieval of recent memories would produce greater hippocampal activation and less neocortical activation, whereas remote memory retrieval would produce greater neocortical activation and diminishing hippocampal activation as cortical representation of remote memories becomes independent of the medial-temporal lobe (Meeter \& Murre, 2004; Ryan et al., 2001). In contrast to these predictions, our current findings suggest greater neocortical activation associated with more recent memories, which parallels our previous findings (Douville et al., 2005), particularly for the right hippocampal complex and parahippocampal gyrus. This neocortical activity may reflect greater processing that is associated with recent memories, perhaps in association with greater input from medial-temporal structures.

In contrast, Multiple Trace Theory (Nadel, Samsonovich, Ryan, \& Moscovitch, 2000; Moscovitch \& Nadel, 1998; Nadel \& Moscovitch, 1997) suggests that the hippocampal formation and the surrounding medial-temporal neocortex play an enduring and parallel role in retrieval of all memories, regardless of age, by forming a hippocampal-neocortical ensemble of memory traces. Reactivations of previously established memory traces, formed by repeated retrievals of the memory, are assumed to be sparse and distributed, with each reactivated trace sharing at least some of the information related to the initial episode. On the basis of this theory, Ryan et al. (2001) have stated that neocortical activation would specifically not be expected to increase with time. In fact, neocortical activation may even decrease in response to retrieval of older information because well-established traces associated with older memories would have established a richer and more diffusely distributed network of memory traces over time relative to recently established traces. The pattern of neocortical activity observed in this study targely fit this prediction.

In the current study, only the right parahippocampal gyrus showed significant differences between the Recent versus Unfamiliar and Remote versus Unfamiliar conditions in our voxelwise analyses. Our previous study (Douville et al., 2005), using the same imaging dataset, focused solely on the hippocampal complex and the parahippocampal gyrus, and found significant activity in both structures bilaterally for the two time epochs relative to the unfamiliar condition. It is important to note that in the Douville et al. (2005) study, we applied less stringent individual voxel probability $(p=.005)$ and minimum cluster size $(0.20 \mathrm{ml})$ thresholds to define activated voxels because the overall search space was limited a priori to the medial-temporal lobe. In the current study, the search space involved the whole brain; as such, we applied more stringent individual voxel probability $(p=.001)$ and cluster size $(0.25 \mathrm{ml})$ thresholds to achieve an overall probability of detecting a falsepositive cluster at the $p=.05$ level. The application of less stringent threshold criteria to uncover hippocampal responses has precedent in previous studies (e.g., Piefke, Weiss, Zilles, Markowitsch, \& Fink, 2003).

\section{Limitations of the Present Study}

From our stimulus development phase (Douville et al., 2005), ratings of depth of semantic knowledge associated with each of the stimulus items did not differ significantly for the recent and remote categories, although occupational category was reported more accurately for the remote category, and knowledge of whether the individual was still living was reported more accurately for the recent category. Nevertheless, it is possible that recent stimuli could be associated with other aspects of semantic knowledge that were not measured in this study that may fade with time. Therefore, we cannot conclusively rule out the possible influence of temporal differences in semantic knowledge of stimuli on our imaging results. However, in the present study, neither accuracy nor RT differed significantly across the recent and remote conditions, tending to argue against the possibility that depth of semantic knowledge may have been systematically reduced in the remote condition relative to the recent condition. In addition, the definition of recent and remote memories is important to consider, as the time periods selected for study could affect the pattern of results. Rekkas and Constable (2005) contrasted autobio- 
graphical episodic memories 2.5 days old versus 8 years old. Although temporally graded neocortical activity was not reported, activation in the parahippocampal, prefrontal, and mid-temporal gyri, and the temporal-parietal junction, posterior cingulate, and precuneus was common to both types of memory retrieval. However, hippocampal activity was greater during recall of remote events, which is contrary to Consolidation Theory. In contrast, Takashima et al. (2006) found a decline in hippocampal activity and a corresponding increase in the ventral medial prefrontal cortex over a 3 -month period. Finally, it is possible that recent memories could be more vivid or "stronger" than remote memories, which could plausibly account for their greater extent of activation. However, Bunge, Burrows, and Wagner (2004) reported a negative correlation between the anterior cingulate cortex (ACC) and the hippocampus, such that increased ACC activity was associated with attempts to recall less vivid memories. That is, the ACC was engaged when processes associated with hippocampal activity required additional input during retrieval of weaker stimuli. In our study, the ACC was activated during both recent and remote conditions, with no difference seen between the two conditions (see Table 1). Further, RTs and accuracy for recent and remote stimuli were not significantly different. Therefore, we do not believe that vividness or strength of memories accounted for the differences in activation pattern across conditions seen in our study.

The extent to which our results would generalize to younger participants is also open to question, although this issue is difficult to conclusively resolve given that age and temporal gradient duration are confounded. In a recent article from our group (Nielson et al., 2006), compared with younger adults, older adults exhibited more extensive and greater activation in most brain regions during retrieval of remotely (1950s-1960s) but continuously famous names (e.g., Frank Sinatra) and recently famous names. That is, older participants showed more extensive and greater activation encompassing largely the same regions as younger participants. These results suggest that at least during recognition of public figures that have been continuously or recently famous, older and younger adults do show a similar pattern of activation. However, older adults exhibited more extensive areas of activation, suggesting functional recruitment to support task performance. Clearly, the age of the memories associated with the remote material differed for the two groups; without a comparable younger group with a similar duration of remote memories to contrast with the older group, the generalizability of our temporal gradient findings to younger participants is difficult to evaluate.

\section{Conclusions}

Maguire et al.'s (2001) proposal that the degree of activation in the neocortex may reflect the degree of integration between a memory trace and contextual information is one possible explanation for the temporally graded neocortical responses observed in our study. We propose an alternative but compatible account for the temporally graded decreases in activity with memory age observed in this study. Greater activity in a given neocortical region would be expected for newer memories, as multiple, diffusely distributed traces have not yet been extensively established. Because older memories have likely undergone multiple reactivations, producing a richer and more efficiently distributed network of traces, reactivation of a memory trace associased with an older memory would activate a substantially more cohesive but distributed network of traces. Therefore, due to their more extensive, diffuse representation, older memories are not as likely to exhibit the same degree of localized activation as a more recently generated memory trace. In fact, they may have become more semanticized with time, making them less dependent on episodic context for their retrieval (Snowden et al., 1996; Warrington \& McCarthy, 1988; Butters \& Cermak, 1986). Recognition of any famous person clearly has aspects of semantic memory (knowledge of facts pertaining to the individual) and autobiographical/episodic memory (personal significance of a public figure or recollection of autobiographical events associated with the famous person) to varying degrees (Westmacott, Black, Freedman, \& Moscovitch, 2004; Westmacott \& Moscovitch, 2003). The relative episodic and semantic characteristics associated with a memory of a public figure might therefore be expected to affect its neural representation over time.

When combined with our previous report (Douville et al, 2005), our current findings suggest that the medial-temporal lobe and neocortical activity may work in concert in the retrieval of relatively recent (within the last 5 years) versus remote (as much as 50 year old) memories. Each act of retrieval of a memory trace may serve to enhance encoding. Regardless of memory age, hippocampal activity would serve as a pointer to the corresponding neocortical representation of the memory trace, thereby reactivating the experiential component of the memory trace and contributing to the further strengthening and stabilization of the memory trace (Frankland \& Bontempi, 2005; Moscovitch et al., 2005). The temporally graded decreases in activity associated with older memories may reflect a decline in associations between memory traces and their associated contextual/experiential information (Maguire et al., 2001) as the neocortical representation of the trace expands and strengthens, consequently, necding less contextual/ experiential input to facilitate recollection. This temporally diminishod activation may also be due to a richer, more efficiently distributed network of memory traces associated with well-established, older, and semanticized memories. Our findings also suggest a possible role of the neocortex in temporally dating items in remote 
memory and in establishing and maintaining memory traces throughout the lifespan.

\section{Acknowledgments}

This study was supported by grants from the National Institutes of Health (R01 AG022304), the Medical College of Wisconsin General Clinical Research Center (M01 RR00058), and the W.M. Keck Foundation. We thank Jill Dorflinger, Sally Durgerian, Cathy Elsinger, Nicole Clos, Kellie Janke, and Amanda Moths for their assistance.

Reprint requests should be sent to John I. Woodard, Department of Psychology, Wayne State University, 5057 Woodwand Ave., 7th floor, Detroit, MI 48202, USA, or via e-mail: john.woodard@ wayne.edu.

\section{REFERENCES}

Amaral, D. G., \& Cowan, W. M. (1980). Subcortical afferents to the hippocampal formation in the monkey. Journal of Comparative Neurology, 189, 573-591.

Bernard, F. A., Bullmore, E. T., Graham, K. S., Thompson, S. A., Hodges, J. R., \& Fletcher, P. C. (2004). The hippocampal region is involved in successful recognition of both remote and recent famous faces. Neuroimage, 22, 1704-1714.

Bernstein, L. J., Beig, S., Siegenthaler, A. L., \& Grady, C. L. (2002). The effect of encoding strategy on the neural correlates of memory for faces. Neuropsycbologia, 40 , 86-98.

Bontempi, B., Laurent-Demir, C., Destrade, C., \& Jaffard, R. (1999). Time-dependent reorganization of brain circuitry underlying long-term memory storage. Nature, 400, 671-675.

Bunge, S. A., Burrows, B., \& Wagner, A. D. (2004). Prefrontal and hippocampal contributions to visual associative recognition: Interactions between cognitive control and episodic retrieval. Brain and Cognition, 56, 141-152.

Butters, N., \& Cermak, L. S. (1986). A case study of the forgetting of autobiographical knowledge: Implications for the study of retrograde amnesia. In Autobiograpbical memory (pp. 253-272). New York: Cambridge University Press.

Conway, M. A., \& Haque, S. (1999). Overshadowing the reminiscence bump: Memories of a struggle for independence. Journal of Adult Development, 6 , 35-44.

Cox, R. (1996). AFNI: Software for analysis and visualization of functional magnetic resonance neuroimages. Compziters and Btomedical Research, 29, 162-173.

Douville, K., Woodard, J. L., Seidenberg, M., Miller, S. K., Leveroni, C. L., Nielson, K. A., et al. (2005). Medial temporal lobe activity for recognition of recent and remote famous names: An event-related fMRI study. Neuropsychologia, 43, 693-703.

Eustache, F., Piolino, P., Giffard, B., Viader, F., De La Sayette, V., Baron, J. C., et al. (2004). "In the course of time": A PET study of the cerebral substrates of autobiographical amnesia in Alzheimer's disease. Brain, 127, 1549-1560.

Fink, G. R, Markowitsch, H. J., Reinkemeier, M., Bruckbauer, T., Kessler, J., \& Heiss, W. D. (1996). Cerebral representation of one's own past: Neural networks involved in autobiographical memory. Journal of Neuroscience, 16, 4275-4282.

Fitzgerald, J. M. (1996). The distribution of self-narrative memories in younger and older adults: Elaborating the self-narrative hypothesis. Aging Neuropsycbology, and Cognition, 3, 229-236.

Fleccher, P. C., Frith, C. D., Grasby, P. M., Shallice, T., Frackowiak, R. S., \& Dolan, R. J. (1995). Brain systems for encoding and retrieval of auditory-verbal memory. An in vivo study in humans. Brain, 118, 401-416.

Fletcher, P. C., \& Henson, R. N. (2001). Brontal lobes and human memory: Insights from functional neuroimaging. Brain, 124, 849-881.

Fletcher, P. C., Shallice, T., Frith, C. D., Frackowiak, R. S., \& Dolan, R. J. (1996). Brain activity during memory retrieval. The influence of imagery and semantic cueing. Brain, 119, 1587-1596.

Folstein, M. F., Folstein, S. E., \& McHugh, P. R. (1975). "Mini-Mental State": A practical method for grading the cognitive state of patients for the clinician-Journal of Psychiatric Research, 12, 189-198.

Forman, S. D., Cohen, J. D., Fitzgerald, M., Eddy, W. F., Mintun, M. A., \& Noll, D. C. (1995). Improved assessment of significant activation in functional magnetic resonance imaging (fMRI): Use of a cluster-size threshold. Magnetic Resonance in Medicine, 33, 636-647.

Frankland, P. W., \& Bontempi, B. (2005). The organization of recent and remote memories. Nature Reviews Neuroscience, 6, 119-130.

Gainotti, G., Almonti, S., Di Betta, A. M., \& Silveri, M. C. (1998). Retrograde amnesia in a patient with retrosplenial tumour. Neurocase, 4, 519-526.

Garoff, R. J., Slotnick, S. D., \& Schacter, D. L. (2005). The neural origins of specific and general memory: The role of the fusiform cortex. Neuropsychologia, 43, 847-859.

Gilboa, A., Winocur, G., Grady, C. L., Hevenor, S. J., \& Moscovitch, M. (2004). Remembering our past: Functional neuroanatomy of recollection of recent and very remote personal events. Cerebral Cortex, 14, 1214-1225.

Goldman-Rakic, P. S., Selemon, L. D., \& Schwartz, M. L. (1984). Dual pathways connecting the dorsolateral prefrontal cortex with the hippocampal formation and parahippocampal cortex in the rhesus monkey. Neuroscience, 12, 719-743.

Gorno-Tempini, M. L., Price, C. J., Josephs, O., Vandenberghe, R., Cappa, S. F., Kapur, N., et al. (1998). The neural systems sustaining face and proper-name processing. Brain, 121, 2103-2118.

Grasby, P. M., Frith, C. D., Friston, K. J., Bench, C., Frackowiak, R. S. J., \& Dolan, R. J. (1993). Functional mapping of brain areas implicated in auditory-verbal memory function. Brain, 116, 1-20.

Greene, J. D., Hodges, J. R, \& Baddeley, A D. (1995). Autobiographical memory and executive function in early dementia of Alzheimer type. Neuropsychologia, 33, 1647-1670.

Haist, F., Bowden Gore, J., \& Mao, H. (2001). Consolidation of human memory over decades revealed by functional magnetic resonance imaging. Nature Neuroscience, 4, $1139-1145$.

Henson, R. N., Rugg, M. D., Shallice, T., Josephs, O., \& Dolan, R. J. (1999). Recollection and familiarity in recognition memory: An event-related functional magnetic resonance imaging study. Journal of Neuroscience, 19, 3962-3972.

Hodges, J. R., Salmon, D. P., \& Butters, N. (1993). Recognition and naming of famous faces in Alzheimer's disease: $A$ cognitive analysis. Neuropsycbologia, 31, 775-788.

Huang, C., Wahlund, L. O., Svensson, L., Winblad, B., \& Julin, P. (2002). Cingulate cortex hypoperfusion predicts Alzheimer's disease in mild cognitive impairment. $B M C$ Neurology, 2, 9.

Ironside, R, \& Guttmacher, M. (1929). The corpus callosum and its tumors. Brain, 52, 442-483. 
Ivanoiu, A., Cooper, J. M., Shanks, M. F., \& Venneri, A. (2004). Retrieval of episodic and semantic autobiographical memories in early Alzheimer's disease and semantic dementia. Cortex, 40, 173-175.

Kazui, H., Hashimoto, M., Hirono, N., Imamura, T., Tanimukai, S., Hanihara, T., et al. (2000). A study of remote memory impairment in Alzheimer's disease by using the family line test. Dementia and Geriatric Cognitive Disorders, 11, 53-58.

Kobayashi, Y., \& Amaral, D. G. (2003). Macaque monkey retrosplenial cortex: II. Cortical afferents. Journal of Comparative Neurology, 466, 48-79.

Kolb, B., \& Walkey, J. (1987). Behavioural and anatomical studies of the posterior parietal cortex in the rat. Bebavioural Brain Research, 23, 127-145.

Kopelman, M. D. (1989). Remote and autobiographical memory, temporal context memory and frontal atrophy in Korsakoff and Alzheimer patients. Neuropsycbologia, $27,437-460$.

Koutstaal, W., Wagner, A. D., Rotte, M., Maril, A., Buckner, R. L., \& Schacter, D. L. (2001). Perceptual specificity in visual object priming: Functional magnetic resonance imaging evidence for a laterality difference in fusiform cortex. Neuropsycbologia, 39, 184-199.

Leveroni, C. L., Seidenberg, M., Mayer, A. R., Mead, L. A., Binder, J. R., \& Rao, S. M. (2000). Neural systems underlying the recognition of familiar and newly learned faces. Journal of Neuroscience, 20, 878-886.

Maddock, R. J. (1999). The retrosplenial cortex and emotion: New insights from functional neuroimaging of the human brain. Trends in Neurosciences, 22, 310-316.

Maddock, R. J., Garrett, A. S., \& Buonocore, M. H. (2001). Remembering familiar people: The posterior cingulate cortex and autobiographical memory retrieval. Neurascience, 104, 667-676.

Maguire, E. A., \& Frith, C. D. (2003). Lateral asymmetry in the hippocampal response to the remoreness of autobiographical memories. Journal of Neuroscience, 23, 5302-5307.

Maguire, E. A., Henson, R. N., Mummery, C. J., \& Frith, C. D. (2001). Activity in prefrontal cortex, not hippocampus, varies parametrically with the increasing remoteness of memories. NeuroReport, 12, 441-444.

McClelland, J. L., McNaughton, B. L., \& O'Reilly, R. C. (1995). Why there are complementary learning systems in the hippocampus and neocortex: Insights from the successes and failures of connectionist models of learning and memory. Psychological Review, 102, 419-457.

Meeter, M., \& Murre, J. M. (2004). Consolidation of long-term memory: Evidence and alternatives. Psychological Bulletin, 130, 843-857.

Morris, R., Pandya, D. N., \& Petrides, M. (1999). Fiber system linking the mid-dorsolateral frontal cortex with the retrosplenial/presubicular region in the rhesus monkey. Journal of Comparative Neurology, 407, 183-192.

Moscovitch, M., \& Nadel, L. (1998). Consolidation and the hippocampal complex revisited: In defense of the multiple-trace model. Current Opinion in Neurobiology, 8, 297-300.

Moscovitch, M., Nadel, L., Winocur, G., Gilboa, A., \& Rosenbaum, R. S. (2006). The cognitive neuroscience of remote episodic, semantic and spatial memory. Current Opinion in Neurobiology, 16, 179-190.

Moscovitch, M., Rosenbaum, R. S., Gilboa, A. Addis, D. R., Westmacott, R., Grady, C., et al. (2005). Functional neuroanatomy of remote episodic, semantic and spatial memory: A unified account based on multiple trace theory. Journal of Anatomy, 207, 35-66.
Nadel, L., \& Moscovitch, M. (1997). Memory consolidation, retrograde amnesia and the hippocampal complex. Current Opinion in Neurobiology, 7, 217-227.

Nadel, L., Samsonovich, A., Ryan, L., \& Moscovitch, M. (2000). Multiple trace theory of human memory: Computational, neuroimaging, and neuropsychological results. Hippocampus, 10, 352-368.

Nielson, K. A., Douville, K. L., Seidenberg, M., Woodard, J. L., Miller, S. K. Franczak, M., et al. (2006). Age-related functional recruitment for famous name recognition: An event-related fMRI study. Neurobiology of Aging, 27, 1494-1504.

Nyberg, L, Tulving, E., Habib, R., Nilsson, L. G., Kapur, S., Houle, S., et al. (1995). Functional brain maps of retrieval mode and recovery of episodic information. NeuroReport, 7 , 249-252.

Oldfield, R. C. (1971). The assessment of handedness: The Edinburgh Inventory. Neuropsychologia, 9, 97-111.

Patterson, K., \& Hodges, J. R. (2000). Semantic dementia: One window on the structure and organisation of semantic memory. In Handbook of neuropsychology: Vol. 2. Memory and its disorders (2nd ed., pp. 313-333). Amsterdam, Netherlands: Elsevier Science.

Piefke, M., Weiss, P. H., Zilles, K., Markowitsch, H. J., \& Fink, G. R. (2003). Differential remoteness and emotional tone modulate the neuml correlates of autobiographical memory. Brain, 126, 650-668.

Pigott, S., \& Milner, B. (1993). Memory for different aspects of complex visual scenes after unilateral temporal- or frontal-lobe resection. Neuropsycbologia, 31, 1-15.

Randolph, C. (1998). Repeatable Battery for the Assessment of Neuropsychological Status. San Antonio: The Psychological Corporation.

Randolph, C., Tierney, M. C., Mohr, E., \& Chase, T. N. (1998). The Repeatable Battery for the Assessment of Neuropsychological Status (RBANS): Preliminary clinical validity. Journal of Clinical and Experimental Neuropsycbology, 20, 310-319.

Reiman, E. M., Caselli, R. J., Chen, K. Alexander, G. E., Bandy, D., \& Frost, J. (2001). Declining brain activity in cognitively normal apolipoprotein $\mathrm{E}$ epsilon 4 heterozygotes: A foundation for using positron emission tomography to efficiently test treatments to prevent Alzheimer's disease. Proceedings of the National Academy of Sciences, U.S.A., 98, 3334-3339.

Reiman, E. M., Caselli, R. J., Yun, L. S., Chen, K. Bandy, D., Minoshima, S., et al. (1996). Preclinical evidence of Alzheimer's disease in persons homozygous for the e- 4 allele for apolipoprotein E. New England Journal of Medicine, 334, 752-758.

Rekkas, P. V., \& Constable, R. T. (2005). Evidence that autobiographic memory retrieval does not become independent of the hippocampus: An fMRI scudy contrasting very recent with remote events. Journal of Cognitive Neuroscience, 17, 1950-1961.

Ribot, T. (1881). Les maladies de la mémoire [The diseases of memory]. Paris: Germer Baillare.

Ridderinkhof, K. R., Ullsperger, M., Crone, E. A., \& Nieuwenhuis, S. (2004). The role of the medial frontal cortex in cognitive control. Science, 306, 443-447.

Rudge, P., \& Warrington, E. K. (1991). Selective impairment of memory and visual perception in splenial tumours. Brain, $114,349-360$.

Rudy, J. W., Biedenkapp, J. C., \& O'Reilly, R. C. (2005). Prefrontal cortex and the organization of recent and remote memories: An alternative view. Learning and Memory, 12, $445-446$.

Rugg, M. D., Fletcher, P. C., Frith, C. D., Frackowiak, R. S., \& Dolan, R. J. (1997). Brain regions supporting intentional and 
incidental memory: A PET study. NeuroReport, 8, 1283-1287.

Ryan, L., Nadel, L., Keil, K., Putnam, K., Schnyer, D., Trouard, T., et al. (2001). Hippocampal complex and retrieval of recent and very remote autobiographical memories: Evidence from functional magnetic resonance imaging in neurologically intact people. Hippocampus, 11, 707-714.

Selemon, L., \& Goldman-Rakic, P. (1988). Common cortical and subcortical targets of the dorsolateral prefrontal and posterior parietal cortices in the rhesus monkey: Evidence for a distributed neural network subserving spatially guided behavior. Journal of Neuroscience, 8, 4049-4068.

Shah, N. J., Marshall, J. C., Zafiris, O., Schwab, A., Zilles, K., Markowitsch, H. J., et al. (2001). The neural correlates of person familiarity. A functional magnetic resonance imaging study with clinical implications, Brain, 124, 804-815.

Shibata, H., \& Yukie, M. (2003). Differential thalamic connections of the posteroventral and dorsal posterior cingulate gyrus in the monkey. European Journal of Neuroscience, 18, 1615-1626.

Simons, J. S., Koutstaal, W., Prince, S., Wagner, A. D., \& Schacter, D. L. (2003). Neural mechanisms of visual object priming: Evidence for perceptual and semantic distinctions in fusiform cortex. Neuroimage, 19, 613-626.

Small, G. W., Ercoli, L. M., Silverman, D. H., Huang, S. C., Komo, S., Bookheimer, S. Y., et al. (2000). Cerebral metabolic and cognitive decline in persons at genetic risk for Alzheimer's disease. Proceedings of the National Academy of Sciences, U.S.A, 97, 6037-6042.

Snowden, J. S., Griffiths, H. L., \& Neary, D. (1996). Semantic-episodic memory interactions in semantic dementia: Implications for retrograde memory function. Cognitive Neuropsychology, 13, 1101-1137.

Sperling, R., Chua, E., Cocchiarella, A, Rand-Giovannetti, E., Poldrack, R., Schacter, D. L., et al. (2003). Putting names to faces: Successful encoding of associative memories activates the anterior hippocampal formation. Neuroimage, 20 , 1400-1410.

Sperling, R A., Bates, J. F., Cocchiarella, A. J., Schacter, D. L., Rosen, B. R., \& Albert, M. S. (2001). Encoding novel face-name associations: A functional MRI study. Human Brain Mapping, 14, 129-139.
Squire, I. R., \& Alvarez, P. (1995). Retrograde amnesia and memory consolidation: A neurobiological perspective. Current Opinion in Neurobiology, 5, 169-177.

Stanton, G. B., Bruce, C. J., \& Goldberg, M. E. (1995). Topography of projections to posterior cortical areas from the macaque frontai eye fields. Journal of Comparative Neurology, 353, 291-305.

Takashima, A, Petersson, K. M., Rutters, F., Tendolkar, I., Jensen, O., Zwarts, M. J., et al. (2006). Declarative memory consolidation in humans: A prospective functional magnetic resonance imaging study. Proceedings of the National Academy of Sciences, U.S.A., 103, 756-761.

Talairach, J., \& Tournoux, P. (1988). A co-planar stereotaxic atlas of a buman brain. Stuttgart: Thieme.

Tanaka, M., Fukuyama, H., Yamauchi, H., Narita, M., Nabatame, H., Yokode, M., et al. (2002). Regional cerebral blood flow abnormalities in nondemented patients with memory impairment. Journal of Neuroimaging, 12, 112-118.

Valenstein, E., Bowers, D., Verfaellie, M., Heilman, K. M., Day, A, \& Watson, R. T. (1987). Retrosplenial amnesia. Brain, 110, 1631-1646.

Wagner, A. D., Shannon, B. J., Kahn, I., \& Buckner, R. L. (2005). Parietal lobe contribucions to episodic memory retrieval. Trends in Cognitive Sciences, 9, 445-453.

Walhovd, K. B., Fjell, A. M., Dale, A. M., Fischl, B., Quinn, B. T., Makris, N., et al. (2006). Regional cortical thickness matters in recall after months more than minutes. Neuroimage, 31 , 1343-1351.

Warrington, E. K., \& McCarthy, R. A. (1988). The fractionation of retrograde amnesia. Brain and Cognition, 7, 184-200.

Westmacott, R., Black, S. E., Freedman, M., \& Moscovitch, M. (2004). The contribution of autobiographical significance to semantic memory: Evidence from Alzheimer's disease, semantic dementia, and amnesia. Neuropsycbologia, 42, $25-48$.

Westmacott, R, \& Moscovitch, M. (2003). The contribution of autobiographical significance to semantic memory. Memony E Cognition, 31, 761-774.

Yonelinas, A. P., Hopfinger, J. B., Buonocore, M. H., Kroll, N. E., \& Baynes, K. (2001). Hippocampal, parahippocampal and occipital-temporal contributions to associative and item recognition memory: An fMRI study. NeuroReport, 12, 359-363. 